\title{
Retraction
}

The article titled "Cardiovascular safety of oral antidiabetic therapy in type 2 diabetes mellitus- review article" by Singh PS et al., published in International Journal of Research in Medical Sciences 2017;5(5):1742-1750, DOI: http://dx.doi.org/10.18203/2320-6012.ijrms20171805 is retracted.

After the publication of the above article, one of the authors reported that some part of the text is plagiarized from his similar article published in Cardiovascular Diabetology, Volume 16 (2017), DOI: https://doi.org/10.1186/s12933-017-0499-5 (Xu J, Rajaratnam R. Cardiovascular safety of non-insulin pharmacotherapy for type 2 diabetes. Cardiovasc Diabetol. 2017 Feb 2;16(1):18. We contacted the author who could not satisfactorily respond to our queries. Since the author could not satisfactorily defend his article and contravened the declaration he made while submitting his manuscript, it was decided to retract the article from International Journal of Research in Medical Sciences and not to consider any manuscript submitted by him in future. 


\title{
Review Article
}

\section{Cardiovascular safety of oral antidiabetic therapy in type 2 diabetes mellitus- review article}

\author{
P. S. Singh*, Sudhir K. Yadav, Himanshu Sharma, Manoj Kumar
}

Department of Medicine, Uttar Pradesh University of Medical Sciences, Saifai, Etawah, Uttar Pradesh, India

Received: 05 March 2017

Accepted: 01 April 2017

*Correspondence:

Dr. P. S. Singh,

E-mail: premshanker0354@gmail.com

Copyright: () the author(s), publisher and licensee Medip Academy. This is an open-access article distributed under the terms of the Creative Commons Attribution Non-Commercial License, which permits unrestricted non-commercial use, distribution, and reproduction in any medium, provided the original work is properly cited.

\section{ABSTRACT}

Cardiovascular disease is the leading cause of morbidity and mortality among patients with type 2 diabetes mellitus (DM). There is twofold increased risk of cardiovascular (CV) mortality among diabetic patients as compared with nondiabetic patients. The glycemic efficacy of anti-diabetic drugs does not necessarily provide cardiovascular safety. Since 2008, US Food and Drug Administration has recommended that new drugs for type 2 DM should undergo clinical trials to demonstrate cardiovascular safety in addition to glycemic benefit. In 2012, European medicine agencies issued a similar recommendation. In this review, we have tried to examine the cardiovascular safety of oral antidiabetic agents in major published trials. Metformin remains the initial drug of choice in type2 DM till date. The sulfonylureas, one of oldest oral anti-diabetic drugs, have adverse cardiovascular events and are gradually being out classed by other second line drugs. The glitazones have been found to have adverse outcome in heart failure. The incretin based drugs have been found to have cardiovascular safety in various trials in recent past and their performances have been reassuring. There is lack of enough cardiovascular outcome data for meglitinides and glucosidase inhibitors. Various current trials have found sodium glucose cotransporter-2 inhibitors to have a potential for cardiovascular benefit. Careful selection of drug therapy with special attention for cardiovascular risk is important in selection and optimization of diabetic therapy.

Keywords: Antidiabetic drugs, Cardiovascular risk, Drug therapy, Oral hypoglycemic drugs, Type 2 diabetes

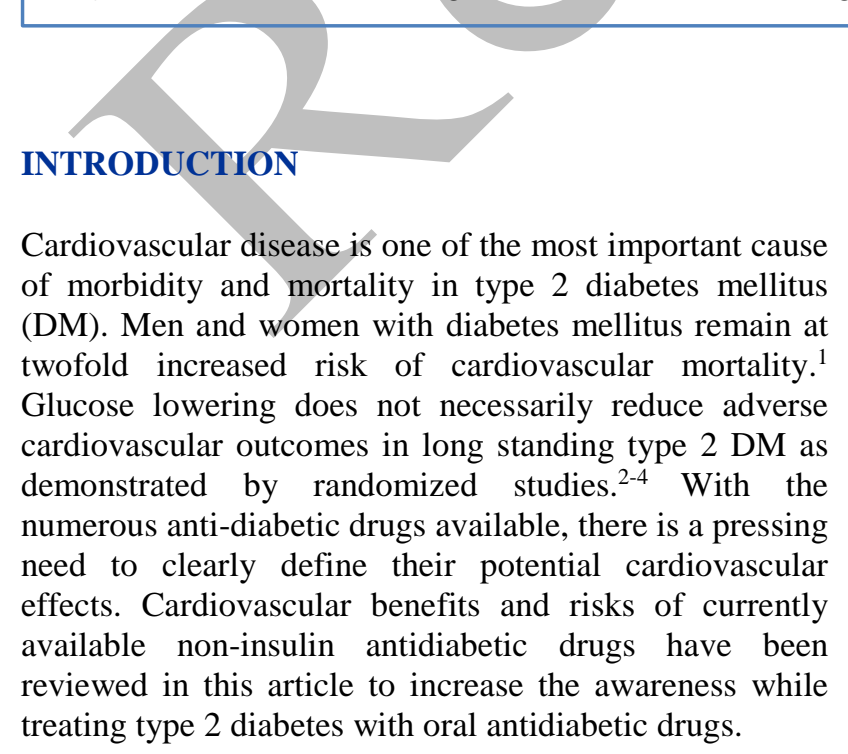

\section{BIGUANIDES}

\section{Metformin}

Metformin inhibits hepatic gluconeogenesis and increases insulin-mediated glucose uptake in peripheral tissues. ${ }^{6-9}$ Metformin reduces mean glycated hemoglobin (HbA1c) by approximately $1.5 \%$ compared to placebo and promotes weight loss of up to $2.5 \mathrm{~kg}$, sustainable over 10 years. ${ }^{9-11}$ Metformin beneficially alters the lipid profile, reducing serum triglyceride and plasma total cholesterol level and slightly increasing serum high density lipoprotein cholesterol levels. ${ }^{11,12}$ Metformin may also have vascular protective effects through increased angiogenesis by improving the angiogenic potential of 
CD34+ cells. $^{12}$ Furthermore, the potential beneficial action of metformin on endothelial function have also been reported.

\section{Cardiovascular safety}

Metformin monotherapy in obese newly diagnosed type 2 DM patients was associated with a $32 \%$ reduction in the aggregate diabetes related end point, including sudden death and myocardial infarction and $36 \%$ reduction in allcause mortality. ${ }^{15}$ This benefit was sustainable, with persistent risk reduction observed in the metformin group for any diabetes related endpoint. ${ }^{5}$ A meta-analysis of randomized trial showed that metformin reduced adverse cardiovascular events (MI, stroke, peripheral artery disease and cardiovascular death) versus placebo/no therapy. ${ }^{16}$ A non-significant trend towards reduced allcause mortality was also noted with metformin monotherapy. ${ }^{16,17}$ This benefit may be especially pronounced in obese patients with a systematic review trial reporting a reduction in all-cause mortality with metformin in this population when compared with sulfonylurea. ${ }^{17-22}$

A systematic review of cohort studies found no increased risk for cardiovascular morbidity and mortality with metformin use across various subgroups of patients compared with placebo or insulin. ${ }^{30,31}$ Thus metformin has an excellent cardiovascular safety profile along with low cost and efficacy and guidelines recommend metformin as the first-line drug therapy of choice for type 2 DM. $^{26}$

\section{INSULIN SECRETAGOGUES}

\section{Sulfonylureas}

The sulfonylureas are most widely prescribed old oral anti-diabetic agents. ${ }^{24,25}$ Second-generation agents include glipizide, glibenclamide and gliclazide. Sulfonylurea monotherapy reduces $\mathrm{HbA1c}$ by $1-2 \%$ but weight gain is almost inevitable. ${ }^{24,25}$ Sulfonylureas gain a mean of $5.3 \mathrm{~kg}$ over 6 years. ${ }^{26-28}$ Glimepiride, a third-generation agent, has at least therapeutic equivalence to the secondgeneration agents, but is less associated with both weight gain and hypoglycemia. ${ }^{29}$

\section{Cardiovascular safety}

Several observational studies have supported an association between sulfonylurea use and increased cardiovascular mortality. ${ }^{32-34}$ A review of 115 randomized trials found a $22 \%$ increased risk of all-cause mortality with sulfonylurea therapy compared with placebo or other anti-diabetic drugs although the overall incidence of major adverse cardiovascular events (MACE) appeared to be unaffected. ${ }^{35}$ Interference with protection from ischemic preconditioning due to blockade of mitochondrial KATP may contribute to the observed association between sulfonylureas and cardiovascular mortality. ${ }^{36}$ The impact of sulfonylureas on cardiovascular outcomes may not be a class effect. There is evidence that whilst first-generation sulfonylureas were associated with increased cardiovascular mortality compared to placebo, no difference was found for second-generation agents. ${ }^{27} \mathrm{~A}$ review of randomized trials showed that gliclazide was associated with a lower risk of all cause and cardiovascular related mortality compared with glibenclamide, suggesting a possible benefit specific for gliclazide. ${ }^{37}$

The newer sulfonylureas (gliclazide and glimepiride) may have a more favourable cardiovascular effect profile than older agents and should be the preferred agents in this class. Overall, due to their low cost and short term glycemic efficacy, the sulfonylureas are still strongly endorsed as second-line agents by international guidelines. ${ }^{23,24,38}$

\section{Meglitinides}

The meglitinides have similar action as sulfonylureas but are pharmacologically distinct in machenism of action. ${ }^{38}$ Currently available meglitinides include repaglinide and nateglinide. These exert similar but milder clinical effects compared to sulfonylureas. ${ }^{39}$

\section{Cardiovascular safety}

There are currently no long-term studies of meglitinides to assess cardiovascular outcome or mortality in type 2 DM. After a median follow up of 5 years, there was no difference between nateglinide and placebo with respect to the core composite cardiovascular outcome. ${ }^{42} \mathrm{~A}$ Danish nation-wide registry based observational analysis showed that mortality and cardio-vascular risk associated with the use of repaglinide, and gliclazide, was similar to metformin. ${ }^{42}$

Meglitinides are associated with less hypoglycemia and weight gain compared with sulfonylureas. ${ }^{45}$

\section{Thiazolidinediones}

The thiazolidinediones (TZDs) are a class of potent insulin-sensitizers which act by regulating gene expression through selective ligand binding of the nuclear transcription factor peroxisome prolifer-ator activated receptor $\mathrm{y}$ (PPARy). ${ }^{44}$ The TZDs lowers HbA1c by $1-$ $1.5 \%$ on average in placebo controlled studies, with low risk of hypoglycemia. ${ }^{44}$ Rosiglitazone and pioglitazone are the currently approved agents in this class. Pioglitazone compared with rosiglitazone is associated with significant improvements in triglyceride and cholesterol profiles. ${ }^{45}$

\section{Cardiovascular safety}

In a meta-analysis of 42 randomized trials, many of which were unpublished clinical trial registry data, 
rosiglitazone was associated with a significant increase in the risk of MI and a non-significant trend for increased cardiovascular mortality. ${ }^{46}$ The highly-publicized study resulted in a boxed warning of myocardial ischemia for rosiglitazone in $2007 .{ }^{46}$ In response, an interim analysis of the Rosiglitazone Evaluated for Cardiac Outcomes and Regulation of Glycemia in Diabetes (RECORD) trial was published. This trial randomized T2 DM patients to rosiglitazone plus either metformin or sulfonylurea or an active control (metformin plus sulfonylurea). ${ }^{44,47}$ No elevated risk for MI or death in the rosiglitazone group was noted at 3.75 years follow-up. ${ }^{47}$ The final analysis showed that after a mean follow up of 5.5 years, rosiglitazone was non-inferior to a combination of metformin and sulfonylurea with regards to the primary endpoint of cardiovascular hospitalization or cardiovascular death but its effect on MI was inconclusive due to small number of events. ${ }^{48}$

Pioglitazone was compared with placebo in the Prospective Pioglitazone Clinical Trial in Macrovascular Events (PROACTIVE) study which randomized 5238 T2DM patients at elevated risk for macrovascular complications. The trial was terminated prematurely after an average follow up of 34.5 months due to significant reduction in the main secondary composite endpoint of all-cause mortality, non-fatal MI, and stroke in the pioglitazone group Pioglitazone also non-significantly reduced the composite primary endpoint of all-cause mortality and various cardiovascular outcomes, including MI, stroke, and vascular interventions.

TZD use has consistently been associated with increased risk of heart failure, as shown in a meta-analysis of 29 placebo controlled trials (5.3 vs $3.7 \%) .51$ In RECORD, rosiglitazone was associated with increased risk of fatal and non-fatal heart failure. ${ }^{48}$ Similar findings were noted for pioglitazone in PROACTIVE. ${ }^{49}$ The Diabetes Reduction Assessment with Ramipril and Rosiglitazone Medication (DREAM) trial also showed that rosiglitazone therapy led to an increase in non-fatal heart failure in patients with impaired glucose tolerance.

Current data suggests increased caution with rosiglitazone use. In contrast, pioglitazone may confer cardiovascular benefits. There is no doubt however that both agents should be avoided in patients with or at risk for heart failure and this is reflected in the latest European heart failure guidelines as a class IIIA recommendation. 53,54

\section{Incretin based drugs}

\section{Dipeptidyl Peptidase-4 Inhibitors (DPP-4 Inhibitors)}

The incretin based drugs include glucose dependent insulinotropic peptide (GIP) and GLP-1 which are insulinotropic gut hormones that modulate the insulin secretory response to food intake in a glucose dependent manner. These are rapidly degraded by circulating enzymes called dipeptidyl peptidase-4 (DPP-4). ${ }^{55-57}$ There are currently 5 FDA approved DPP-4 inhibitors: sitagliptin, saxagliptin, linagliptin alogliptin and vildagliptin. A meta-analysis reported $0.74 \% \mathrm{HbA} 1 \mathrm{c}$ reduction when treatment with sitagliptin. The DPP-4 inhibitors, otherwise known as the gliptins, are generally considered to have a neutral effect on weight. ${ }^{58,59}$

\section{Cardiovascular safety}

The randomized trial was carried out in 16,492 patients with T2DM and either a history of cardiovascular disease or multiple vascular risk factors on saxagliptin or placebo along with conventional therapy. After a median follow up of 2.1 years, there was no difference in the primary composite end-point of cardiovascular death, non-fatal MI or non-fatal ischemic stroke between groups for superiority. However, in the pre-specified secondary end points analysis, heart failure hospitalization was more common in the saxagliptin group ( 3.5 vs $2 \cdot 8$ ), although this increased risk subsided by $10-11$ months after randomization. ${ }^{60,61}$

In randomized trial of 5380 patients with T2DM and recent acute coronary syndrome in the last 15-90 days, alogliptin was non inferior to placebo with regards to the combined primary outcome of cardiovascular death, nonfatal MI or non-fatal stroke after a median follow up of 18 months. ${ }^{62}$ A post hoc analysis showed that alogliptin had no effect on heart failure outcomes, including a composite of cardiovascular death and heart failure hospitalization. ${ }^{63}$

In the trial to evaluate cardiovascular outcome after treatment with sitagliptin (TECOS) study, which randomized 14,671 patients with T2DM, sitagliptin was non-inferior to placebo for the primary composite outcome of cardiovascular death, non-fatal MI, non-fatal stroke or hospitalization for unstable angina with no difference in hospitalization rates for heart failure. ${ }^{64}$ Sitgaliptin has also been shown to reduce blood pressure and improve albuminuria in a prospective study of Japanese patients with T2DM. ${ }^{65}$ In addition, long-term use of sitagliptin up to 2 years did not adversely alter endothelial function in patients with T2DM. ${ }^{66}$

The cardiovascular safety profile of linagliptin was investigated in a large patient level pooled safety analysis of 19 clinical trials which concluded that linagliptin was not associated with increased cardiovascular risk versus pooled active comparators or placebo in patients with T2DM, irrespective of background therapy. ${ }^{67}$

A meta-analysis concluded that there was a slightly increased risk of hospitalization for heart failure in gliptin users compared with placebo68. However, the Canadian Network for Observational Drug Effect Studies (CNODES) retrospectively analyzed administrative electronic health records of nearly 1.5 million patients and concluded that DPP-4 inhibitors did not increase the 
rate of heart failure hospitalization compared with oral anti-diabetic drug combinations among patients with or without a history of heart failure. ${ }^{69-71}$ Furthermore, patients treated with gliptins in a comprehensive national cohort of diabetic patients in Taiwan had lower cardiovascular risk. ${ }^{71}$ FDA safety review recommends considering discontinuation of specifically saxagliptin or alogliptin in patients who develops heart failure. ${ }^{72}$ The DPP-4 inhibitors are safe in terms of cardiovascular endpoints but their effect on the risk of heart failure remains uncertain.

\section{Glucagon like peptide-1 agonists}

The GLP-1 agonists are parenterally administered drugs that directly activate the GLP-1 receptor and are highly resistant to degradation by DPP-4. Currently available agents include: exenatide, liraglutide, albiglutide, lixisenatide, and dulaglutide. All are FDA approved with the exception of lixisenatide which is approved in Europe. GLP-1 agonists, when compared to placebo, reduced $\mathrm{HbA} 1 \mathrm{c}$ by about $1 \%$ and resulted in $1.5-2.5 \mathrm{~kg}$ weight loss over 30 weeks. ${ }^{73}$ In addition, treatment with GLP-1 agonists have been shown to further favorably alter the metabolic profile through modest reductions in low-density-lipoprotein cholesterol, total cholesterol and triglycerides as well as reductions in systolic blood pressure, although this may be accompanied by a compensatory increase in heart rate. ${ }^{74,75}$

\section{Cardiovascular safety}

The experimental models of ischemia and reperfusion have shown improved post-ischemic myocardial contractile dysfunction and reduced infarct size with constant infusions of GLP-1. ${ }^{76}$ In the clinical setting, similar positive effects have been observed to various degrees in pilot studies, and the mechanism was thought to be related to reduced apoptosis and nuclear oxidative stress and improvement in myocardial glucose metabolism. ${ }^{77}$

The Evaluation of Lixisenatide in Acute Coronary Syndrome (ELIXA) trial randomized 6068 patients with T2DM and an acute coronary event within the last 180 days to receive lixisenatide or placebo on top of standard of care. After a median follow-up of 25 months, there was no difference in the primary composite end-point of cardiovascular death, non-fatal MI, non-fatal stroke or hospitalization for unstable angina between groups and no difference in heart failure hospitalizations. ${ }^{78}$ In the liraglutide effect and action in diabetes: Evaluation Of Cardiovascular Outcome Results (LEADER) trial, which randomized 9340 T2DM patients with high cardiovascular risk, liraglutide reduced the primary composite endpoint of cardiovascular death, non-fatal MI or non-fatal stroke compared to placebo after a median follow-up of 3years. ${ }^{79,80}$ Although not currently FDA approved, semaglutide, a once-weekly GLP-1 agonist, was non-inferior to placebo after 26 months follow up among 3297 patients with T2DM in the Trial to Evaluate Cardiovascular and Other Long-term Outcomes with Semaglutide in Subjects with Type 2 Diabetes (SUSTAIN-6) with regards to the primary composite endpoint of cardiovascular death, non-fatal MI and nonfatal stroke. ${ }^{81}$ Notably, majority of the trial patients had established cardiovascular disease, stage 3 or higher chronic kidney disease, or both at baseline. Despite the lack of definitive randomized data, dulaglutide, another once-weekly long-acting GLP-1 agonist, was not associated with an increased cardiovascular risk in a meta-analysis of phase 2 and phase 3 trials. ${ }^{82}$

CNODES study also showed that GLP-1 agonists did not increase heart failure hospitalization among patients with or without a history of heart failure. ${ }^{69}$ In fact, GLP-1 infusion has been associated with improvements in left ventricular function in heart failure in both preclinical and clinical settings. ${ }^{77}$

\section{Sodium glucose cotransporter-2 inhibitors}

The sodium glucose cotransporter-2 (SGLT-2) is expressed in the proximal tubule and mediates reabsorption of up to $98 \%$ of urinary glucose. ${ }^{75,79,81,82}$ Inhibition of SGLT-2 lowers blood glucose by promoting renal glucose excretion, which is independent of $\beta$-cell function and thus carries a low risk for hypoglycemia. ${ }^{77,78,80,82}$ Currently, 3 agents are approved in the United States and Europe: dapagliflozin, canagliflozin, and empagliflozin. SGLT-2 inhibitors reduce $\mathrm{HbA} 1 \mathrm{c}$ by $0.5-0.7 \%$ compared with placebo. ${ }^{75-82}$ and promotes weight loss of 2-3 kg over 12 weeks. It has a modest beneficial effect on the lipid profile through an increase in high density lipoprotein cholesterol and decrease in triglycerides. In part due to the osmotic diuresis, SGLT-2 inhibitors also significantly reduce both systolic and diastolic blood pressure without an increase in heart rate.

\section{Cardiovascular safety}

In the only cardiovascular outcomes trial of SGLT-2 inhibitors reported to date, the randomized empagliflozin cardiovascular outcome event trial in type 2 diabetes mellitus patients (EMPA-REG OUTCOME) trial of 7020 patients with T2DM and established cardiovascular disease showed that after a median follow up of 3.1 years, empagliflozin was associated with a reduction in the primary composite endpoint of cardiovascular mortality, nonfatal MI or nonfatal stroke compared with placebo and cardiovascular mortality was also observed in the empagliflozin group. ${ }^{79-82}$ Further analysis showed a $34 \%$ relative risk reduction of a composite of heart failure hospitalization or cardiovascular death with empagliflozin. Driven mainly by these results, a metaanalysis of data from regulatory submissions and published trials suggested net protection of SGLT-2 inhibitors against cardiovascular outcomes and death. ${ }^{80-82}$ Furthermore, empagliflozin has an excellent long term 
safety and tolerability profile. A study of empagliflozin monotherapy for $\geq 76$ weeks in T2DM patients showed a lower rate of drug discontinuation due to adverse events compared with placebo. ${ }^{8}$

SGLT-2 inhibitors are currently favoured as the second line agent of choice in T2DM patients with a history of cardiovascular disease.

\section{Alpha glucosidase inhibitors}

The alpha glucosidase inhibitors (AGIs) lower blood glucose through competitive blockade of intestinal alpha glucosidases which convert complex carbohydrates into monosaccharides. This results in a modified intestinal absorption of carbohydrates and consequently a slower rise in post-prandial blood glucose. ${ }^{83,84}$ Available agents include acarbose, miglitol and voglibose. A Cochrane meta-analysis reported a $0.8 \% \mathrm{HbA} 1 \mathrm{c}$ reduction and no clinically relevant effects on lipids or body weight when acarbose, the most widely prescribed AGI, was compared to placebo. ${ }^{83-85}$ In addition, acarbose may also have beneficial effects on endothelial function by obtunding post prandial glucotoxicity. Miglitol, whilst having similar glycemic efficacy, may have a greater effect on reducing 1 hour post-prandial glucose levels than other AGIs. A study of 47 Japanese patients with T2DM showed that switching from other AGIs to miglitol for 3 months significantly improved glucose fluctuations and reduced serum concentrations of inflammatory cytokines. Miglitol has also been shown to reduce waist circumference and in particular visceral fat in patients with metabolic syndrome..$^{85,86}$

\section{Cardiovascular safety}

The Study to Prevent Non-insulin-dependent Diabetes Mellitus (STOP-NIDDM) trial randomized 1429 patients with impaired glucose tolerance and showed that after a mean follow up of 3.3 years, acarbose treatment was associated with a significant risk reduction in the development of diabetes and hypertension compared to placebo. Although not initially powered to draw conclusions on cardiovascular outcomes, acarbose treatment was also associated with a reduction in the development of the composite outcome of cardiovascular events which includes cardiovascular death, MI, stroke, heart failure, peripheral vascular disease and revascularization.

\section{CONCLUSION}

Favorable glycemic efficacy does not necessarily translate to favorable cardiovascular outcomes. Clinicians must therefore make careful informed decisions based on the cardiovascular effects of the various antidiabetic drugs when prescribing OHA. Based on current evidence, metformin should remain the first line drug of choice in T2DM, being the most extensively studied and demonstrating excellent cardiovascular safety even with long term use. Although evidence for the cardiovascular safety of sulfonylureas are inconsistent, the firstgeneration agents are probably associated with net harm and should be avoided. Newer generation sulfonylureas have a comparatively more favorable cardiovascular profile but weight gain remains a concern. The meglitinides and AGIs lack cardiovascular safety data in T2DM and should therefore be reserved in favour of other second line agents. Among the TZDs, rosiglitazone may be associated with an increased risk of MI while pioglitazone may have beneficial cardiovascular effects. Both are however contraindicated in heart failure. The incretin based drugs have been at the forefront of this era of cardiovascular safety trials and have been extensively studied. Current evidence suggests that the gliptins have neutral overall cardiovascular effect but may increase risk of heart failure particularly saxagliptin. Among the GLP1 agonists, liraglutide may have beneficial effects on cardiovascular outcomes but this requires further validation. Similarly, the SGLT-2 inhibitors have shown promising results with empagliflozin and may potentially confer cardiovascular benefit, although additional data is needed to substantiate this. With results of several large ongoing randomized trials expected in the coming years, will continue to help and guide clinicians in making the best decision in reducing the cardiovascular risk of their diabetic patients.

\section{Funding: No funding sources}

Conflict of interest: None declared

Ethical approval: Not required

\section{REFERENCES}

1. Gerstein HC, Miller ME, Byington RP, Goff DC Jr, Bigger JT, Buse JB, et al. Effects of intensive glucose lowering in type 2 diabetes. N Engl J Med. 2008;358(24):2545-59.

2. Patel A, MacMahon S, Chalmers J, Neal B, Billot L, Woodward M, et al. Intensive blood glucose control and vascular outcomes in patients with type 2 diabetes. N Engl J Med. 2008;358(24):2560-72.

3. Duckworth W, Abraira C, Moritz T, Reda D, Emanuele N, Reaven PD, et al. Glucose control and vascular complications in veterans with type 2 diabetes. N Engl J Med. 2009;360(2):129-39.

4. Holman RR, Paul SK, Bethel MA, Matthews DR, Neil HA. 10-year follow up of intensive glucose control in type 2 diabetes. $\mathrm{N}$ Engl $\mathrm{J}$ Med. 2008;359(15):1577-89.

5. Hiatt WR, Kaul S, Smith RJ. The cardiovascular safety of diabetes drugs insights from the rosiglitazone experience. $\mathrm{N}$ Engl $\mathrm{J}$ Med. 2013;369(14):1285-89.

6. DeFronzo RA, Goodman AM. Efficacy of metformin in patients with non-insulin dependent diabetes mellitus. The Multicenter Metformin Study Group. N Engl J Med. 1995;333(9):541-49.

7. Knowler WC. 10-year follow up of diabetes incidence and weight loss in the Diabetes 
Prevention Program Outcomes Study. Lancet. 2009;374(9702):1677-86.

8. Bailey CJ, Turner RC. Metformin. N Engl J Med. 1996;334(9):574-79.

9. Ahmed FW, Rider R, Glanville M, Narayanan K, Razvi S, Weaver JU et al. Metformin improves circulating endothelial cells and endothelial progenitor cells in type 1 diabetes: MERIT study. Cardiovasc Diabetol. 2016;15(1):116.

10. United Kingdom Prospective Diabetes Study. 34: effect of intensive blood glucose control with metformin on complications in overweight patients with type 2 diabetes. The Lancet. 1998;352(9131):854-65.

11. Lamanna C, Monami M, Marchionni N, Mannucci E. Effect of metformin on cardiovascular events and mortality: a meta-analysis of randomized clinical trials. Diabetes Obes Metab. 2011;13(3):221-38.

12. Saenz A, Fernandez-Esteban I, Mataix A, Ausejo M, Roque M, Moher D. Metformin monotherapy for type 2 diabetes mellitus. Cochrane Database Syst Rev. 2005;3:CD002966.

13. Eurich DT, Majumdar SR, McAlister FA, Tsuyuki RT, Johnson JA. Changes in labelling for metformin use in patients with type 2 diabetes and heart failure: documented safety outweighs theoretical risks. Open Medicine. 2011;5(1):e33-e34.

14. Eurich DT, Weir DL, Majumdar SR, Tsuyuki RT, Johnson JA, Tjosvold L, et al. Comparative safety and effectiveness of metformin in patients with diabetes mellitus and heart failure: systematic review of observational studies involving 34,000 patients. Circ Heart Fail. 2013;6(3):395-402.

15. Kao J, Tobis J, McClelland RL, Heaton MR, Davis BR, Holmes DR Jr, et al. Relation of metformin treatment to clinical events in diabetic patients undergoing percutaneous intervention. Am J Cardiol. 2004;93(11):1347-50.

16. Goergen SK, Rumbold G, Compton G, Harris C. Systematic review of current guidelines on risk of lactic acidosis after administration of contrast medium for patients receiving metformin. Radiology. 2010;254(1):261-69.

17. Baerlocher MO, Asch M, Myers A. Five things to know about metformin and intravenous contrast. Can Med Assoc J. 2013;185(1):E78.

18. Inzucchi SE, Bergenstal RM, Buse JB, Diamant M, Ferrannini E, Nauck $M$, et al. Management of hyperglycemia in type 2 diabetes, 2015: a patientcentered approach: update to a position statement of the American Diabetes Association and the European Association for the Study of Diabetes. Diabetes Care. 2015;38(1):140-49.

19. Garber AJ, Abrahamson MJ, Barzilay JI, Blonde L, Bloomgarden ZT, Bush MA, et al. Consensus Statement by the American Association of Clinical Endocrinologists and American College of Endocrinology on the Comprehensive Type 2 Diabetes Management Algorithm-2016 Executive Summary. Endocr Pract. 2016;22(1):84-113.
20. Sola D, Rossi L, Schianca GPC, Maffioli P, Bigliocca M, Mella R, et al. Sulfonylureas and their use in clinical practice. Archives of Medical Science: AMS. 2015;11(4):840-8.

21. Proks P, Reimann F, Green N, Gribble F, Ashcroft1et F. Sulfonylurea Stimulation of Insulin Secretion. Diabetes. 2002;51(Supplement 3):368-76.

22. Hemmingsen B, Schroll JB, Lund SS, Wetterslev J, Gluud C, Vaag A, et al. Sulphonylurea monotherapy for patients with type 2 diabetes mellitus. Cochrane Database Syst Rev. 2013;4:9008.

23. United Kingdom Prospective Diabetes Study. 24: a 6-year, randomized, controlled trial comparing sulfonylurea, insulin and metformin therapy in patients with newly diagnosed type 2 diabetes that could not be controlled with diet therapy. Ann Intern Med. 1998;128(3):165.

24. Lawrence CL, Rainbow RD, Davies NW, Standen NB. Effect of metabolic inhibition on glimepiride block of native and cloned cardiac sarcolemmal K(ATP) channels. Br J Pharmacol. 2002;136(5):746-52.

25. American Diabetes Association. A study of the effects of hypoglycemic agents on vascular complications in patients with adult onset diabetes: VI Supplementary report on nonfatal events in patients treated with tolbutamide. Diabetes. 1976;25(12):1129-53.

26. Garratt KN, Brady PA, Hassinger NL, Grill DE, Terzic A, Holmes DR Jr. Sulfonylurea drugs increase early mortality in patients with diabetes mellitus after direct angioplasty for acute myocardial infarction. J Am Coll Cardiol. 1999;33(1):119-24.

27. Simpson SH, Majumdar SR, Tsuyuki RT, Eurich DT, Johnson JA. Dose response relation between sulfonylurea drugs and mortality in type 2 diabetes mellitus: a population based cohort study. Can Med Assoc J. 2006;174(2):169-74.

28. Roumie CL, Hung AM, Greevy RA, Grijalva CG, Liu X, Murff HJ, et al. Comparative effectiveness of sulfonylurea and metformin monotherapy on cardiovascular events in type 2 diabetes mellitus: a cohort study. Ann Intern Med. 2012;157(9):601-10.

29. Monami M, Genovese S, Mannucci E. Cardiovascular safety of sulfonylu-reas: a metaanalysis of randomized clinical trials. Diabetes Obes Metab. 2013;15(10):938-53.

30. Giblett JP, Axell RG, White PA, Clarke SJ, McCormick L, Read PA, et al. Glucagon-like peptide-1 derived cardioprotection does not utilize a KATP-channel dependent pathway: mechanistic insights from human supply and demand ischemia studies. Cardiovasc Diabetol. 2016;15:99.

31. Simpson SH, Lee J, Choi S, Vandermeer B, Abdelmoneim AS, Featherstone TR. Mortality risk among sulfonylureas: a systematic review and network meta-analysis. Lancet Diabetes Endocrinol. 2015;3(1):43-51. 
32. Azimova K, Juan SZ, Mukherjee D. Cardiovascular safety profile of currently available diabetic drugs. Ochsner J. 2014;14(4):616-32.

33. Black C, Donnelly P, McIntyre L, Royle PL, Shepherd JP, Thomas S. Meglitinide analogues for type 2 diabetes mellitus. Cochrane Database Syst Rev. 2007;2:4654.

34. Holman RR, Haffner SM, McMurray JJ, Bethel MA, Holzhauer B, Hua TA, et al. Effect of nateglinide on the incidence of diabetes and cardiovascular events. N Engl J Med. 2010;362(16):1463-76.

35. Schramm TK, Gislason GH, Vaag A, Rasmussen JN, Folke F, Hansen ML, et al. Mortality and cardiovascular risk associated with different insulin secretagogues compared with metformin in type 2 diabetes, with or without a previous myocardial infarction: a nation-wide study. Eur Heart J. 2011;32(15):1900-8.

36. Ferrannini E, DeFronzo RA. Impact of glucoselowering drugs on cardio-vascular disease in type 2 diabetes. Eur Heart J. 2015;36(34):2288-96.

37. Yki-Jarvinen H. Thiazolidinediones. N Engl J Med. 2004;351(11):1106-18.

38. Nissen SE, Wolski K. Effect of rosiglitazone on the risk of myocardial infarction and death from cardiovascular causes. N Engl J Med. 2007;356(24):2457-71.

39. Home PD, Pocock SJ, Beck-Nielsen H, Gomis R, Hanefeld M, Jones NP, et al. Rosiglitazone evaluated for cardiovascular outcomes- an interim analysis. N Engl J Med. 2007;357(1):28-38.

40. Home PD, Pocock SJ, Beck-Nielsen H, Curtis PS, Gomis R, Hanefeld M, et al. Rosiglitazone evaluated for cardiovascular out-comes in oral agent combination therapy for type 2 diabetes (RECORD): a multicentre, randomised, open-label trial. Lancet. 2009;373(9681):2125-35.

41. Dormandy JA, Charbonnel B, Eckland DJ, Erdmann E, Massi-Benedetti M, Moules IK, et al. Secondary prevention of macrovascular events in patients with type 2 diabetes in the PROactive Study (PROspective pioglitAzone Clinical Trial In macroVascular Events): a randomised controlled trial. Lancet. 2005;366(9493):1279-89.

42. Hernandez AV, Usmani A, Rajamanickam A, Moheet A. Thiazolidinediones and risk of heart failure in patients with or at high risk of type 2 diabetes mellitus: a meta-analysis and metaregression analysis of placebo-controlled randomized clinical trials. Am J Cardiovasc Drugs. 2011;11(2):115-28.

43. Gerstein HC, Yusuf S, Holman RR, Bosch J, Anand $\mathrm{S}$, Avezum A, et al. Effect of rosiglitazone on the frequency of diabetes in patients with impaired glucose tolerance or impaired fasting glucose: a randomised controlled trial. Lancet. 2006;368(9541):1096-1105.

44. Ponikowski P, Voors AA, Anker SD, Bueno H, Cleland JG, Coats AJ, et al. 2016 ESC Guidelines for the diagnosis and treatment of acute and chronic heart failure: The Task Force for the diagnosis and treatment of acute and chronic heart failure of the European Society of Cardiology (ESC) Developed with the special contribution of the Heart Failure Association (HFA) of the ESC. Eur Heart J. 2016;22(7):77-80.

45. Krische D. The glitazones: proceed with caution. West J Med. 2000;173(1):54-7.

46. Kim W, Egan JM. The role of incretins in glucose homeostasis and diabetes treatment. Pharmacol Rev. 2008;60(4):470-512.

47. Amori RE, Lau J, Pittas AG. Efficacy and safety of incretin therapy in type 2 diabetes: systematic review and meta-analysis. JAMA. 2007;298(2):194206.

48. Craddy P, Palin HJ, Johnson KI. Comparative effectiveness of dipepti-dylpeptidase- 4 inhibitors in type 2 diabetes: a systematic review and mixed treatment comparison. Diabetes Ther. 2014;5(1):141.

49. Davidson JA. Advances in therapy for type 2 diabetes: GLP-1 receptor agonists and DPP-4 inhibitors. Cleve Clin J Med. 2009;76(Suppl 5):2838.

50. Fadini GP, Avogaro A. Cardiovascular effects of DPP-4 inhibition: beyond GLP-1. Vasc Pharmacol. 2011;55(13):10-6.

51. Scirica BM, Bhatt DL, Braunwald E, Steg PG, Davidson J, Hirshberg B, et al. Saxagliptin and cardiovascular outcomes in patients with type 2 diabetes mellitus. $\mathrm{N}$ Engl J Med. 2013;369(14):1317-26.

52. Scirica BM, Braunwald E, Raz I, Cavender MA, Morrow DA, Jarolim P, et al. Heart failure, saxagliptin, and diabetes mellitus: observations from the SAVOR-TIMI 53 randomized trial. Circulation. 2014;130(18):1579-88.

53. White WB, Cannon CP, Heller SR, Nissen SE, Bergenstal RM, Bakris GL, et al. Alogliptin after acute coronary syndrome in patients with type 2 diabetes. N Engl J Med. 2013;369(14):1327-35.

54. Zannad F, Cannon CP, Cushman WC, Bakris GL, Menon V, Perez AT, et al. Heart failure and mortality outcomes in patients with type 2 diabetes taking alogliptin versus placebo in EXAM-INE: a multicentre, randomised, double-blind trial. Lancet. 2015;385(9982):2067-76.

55. Green JB, Bethel MA, Armstrong PW, Buse JB, Engel SS, Garg J, et al. Effect of Sitagliptin on Cardiovascular Outcomes in Type 2 Diabetes. N Engl J Med. 2015;373(3):232-42.

56. Nakamura $T$, Iwanaga $Y$, Miyaji $Y$, Nohara R, Ishimura T, Miyazaki S. Cardiovascular efficacy of sitagliptin in patients with diabetes at high risk of cardiovascular disease: a 12-month follow-up. Cardiovasc Diabetol. 2016;15:54-9.

57. Maruhashi T, Higashi Y, Kihara Y, Yamada H, Sata $\mathrm{M}$, Ueda $\mathrm{S}$ et al. Long-term effect of sitagliptin on endothelial function in type 2 diabetes: a sub- 
analysis of the PROLOGUE study. Cardiovasc Diabetol. 2016;15(1):134-9.

58. Rosenstock J, Marx N, Neubacher D, Seck T, Patel $\mathrm{S}$, Woerle HJ, et al. Cardiovascular safety of linagliptin in type 2 diabe-tes: a comprehensive patient-level pooled analysis of prospectively adjudicated cardiovascular events. Cardiovasc Diabetol. 2015;14:57.

59. Li L, Li S, Deng K, Liu J, Vandvik PO, Zhao P, et al. Dipeptidyl peptidase-4 inhibitors and risk of heart failure in type 2 diabetes: systematic review and meta-analysis of randomised and observational studies. BMJ. 2016;352:610.

60. Filion KB, Azoulay L, Platt RW, Dahl M, Dormuth $\mathrm{CR}$, Clemens KK, et al. A multicenter observational study of incretin-based drugs and heart failure. $\mathrm{N}$ Engl J Med. 2016;374(12):1145-54.

61. Toh S, Hampp C, Reichman ME, Graham DJ, Balakrishnan S, Pucino F, et al. Risk for hospitalized heart failure among new users of saxagliptin, sitagliptin, and other antihyperglycemic drugs: a retrospective cohort study. Ann Intern Med. 2016;164(11):705-14.

62. Ou HT, Chang KC, Li CY, Wu JS. Risks of cardiovascular diseases associated with dipeptidyl peptidase- 4 inhibitors and other antidiabetic drugs in patients with type 2 diabetes: a nation-wide longitudinal study. Cardiovasc Diabetol. 2016;15:41.

63. Shyangdan DS, Royle P, Clar C, Sharma P, Waugh N, Snaith A. Glucagon-like peptide analogues for type 2 diabe-tes mellitus. Cochrane Database Syst Rev. 2011;10:6423.

64. Sun F, Wu S, Wang J, Guo S, Chai S, Yang Z, et al. Effect of glucagon-like peptide-1 receptor agonists on lipid profiles among type 2 diabetes: a systematic review and network meta-analysis. Clin Ther. 2015;37(1):225-41.

65. Katout M, Zhu H, Rutsky J, Shah P, Brook RD, Zhong J, et al. Effect of GLP-1 mimetics on blood pressure and rela-tionship to weight loss and glycemia lowering: results of a systematic metaanalysis and meta-regression. Am J Hypertens. 2014;27(1):130-39.

66. Angeli FS, Shannon RP. Incretin-based therapies: can we achieve glyce-mic control and cardioprotection? J Endocrinol. 2014;221(1):17-30.

67. Pfeffer MA, Claggett B, Diaz R, Dickstein K, Gerstein HC, Køber LV, et al. Lixisenatide in patients with type 2 diabetes and acute coronary syndrome. N Engl J Med. 2015;373(23):2247-57.

68. Marso SP, Daniels GH, Brown-Frandsen K, Kristensen P, Mann JF, Nauck MA, et al. Liraglutide and cardiovascular outcomes in type 2 diabetes. N Engl J Med. 2016;375(4):311-22.

69. Kumarathurai P, Anholm C, Nielsen OW, Kristiansen OP, Molvig J, Madsbad S, et al. Effects of the glucagon-like peptide-1 receptor agonist liraglutide on systolic function in patients with coronary artery disease and type 2 diabetes: a randomized double-blind placebo-controlled crossover study. Cardiovasc Diabetol. 2016;15(1):105.

70. Marso SP, Bain SC, Consoli A, Eliaschewitz FG, Jódar E, Leiter LA, et al. Semaglutide and cardiovascular outcomes in patients with type 2 diabetes. N Engl J Med. 2016;375(19):1834-44.

71. Ferdinand KC, Botros FT, Atisso CM, Sager PT, et al. Cardiovascular safety for once-weekly dulaglutide in type 2 diabetes: a pre-specified metaanalysis of prospectively adju-dicated cardiovascular events. Cardiovasc Diabetol. 2016;15:38.

72. Clar C, Gill JA, Court R, Waugh N. Systematic review of SGLT2 receptor inhibitors in dual or triple therapy in type 2 diabetes. BMJ Open. 2012;2(5):1007.

73. Hanefeld M, Forst T. Dapagliflozin, an SGLT2 inhibitor, for diabetes. Lancet. 2010;375(9733):2196-98.

74. Musso G, Gambino R, Cassader M, Pagano G. A novel approach to control hyperglycemia in type 2 dia-betes: sodium glucose co-transport (SGLT) inhibitors: systematic review and meta-analysis of randomized trials. Ann Med. 2012;44(4):375-93.

75. Vasilakou D, Karagiannis T, Athanasiadou E, Mainou M, Liakos A, Bekiari E et al. Sodiumglucose cotransporter 2 inhibitors for type 2 diabetes: a systematic review and meta-analysis. Ann Intern Med. 2013;159(4):262-74.

76. Hasan FM, Alsahli M, Gerich JE. SGLT2 inhibitors in the treatment of type 2 diabetes. Diabetes Res Clin Pract. 2014;104(3):297-322.

77. Baker WL, Smyth LR, Riche DM, Bourret EM, Chamberlin KW, White WB, et al. Effects of sodium-glucose co-transporter 2 inhibitors on blood pressure: a systematic review and meta-analysis. J Am Soc Hypertens. 2014;8(4):262-75.

78. Oelze M, Kröller-Schön S, Welschof P, Jansen T, Hausding M, Mikhed Y, et al. The sodium glucose co-transporter 2 inhibitor empagliflozin improves diabetes induced vascular dysfunction in the streptozotocin diabetes rat model by interfering with oxidative stress and glucotoxicity. PLoS ONE. 2014;9(11):2394.

79. Fitchett D, Zinman B, Wanner C, Lachin JM, Hantel S, Salsali A, et al. Heart failure outcomes with empagliflozin in patients with type 2 diabetes at high cardiovascular risk: results of the EMPA REG OUTCOME (R) trial. Eur Heart J. 2016;37(19):1526-34.

80. Wu JH, Foote C, Blomster J, Toyama T, Perkovic $\mathrm{V}$, Sundström J, et al. Effects of sodium glucose cotransporter-2 inhibitors on cardiovascular events, death and major safety outcomes in adults with type 2 diabetes: a systematic review and meta-analysis. Lancet Diabetes Endocrinol. 2016;4(5):411-19.

81. Roden M, Merker L, Christiansen AV, Roux F, Salsali A, Gabriel Kim G, et al. Safety, tolerability and effects on cardiometabolic risk factors of 
empagliflozin monotherapy in drug naive patients with type 2 diabetes: a double-blind extension of a Phase III randomized controlled trial. Cardiovasc Diabetol. 2015;14:154-60.

82. Sonesson C, Johansson PA, Johnsson E, GauseNilsson I. Cardiovascular effects of dapagliflozin in patients with type 2 diabetes and different risk categories: a meta-analysis. Cardiovasc Diabetol. 2016;15:37-41.

83. Chiasson JL, Josse RG, Gomis R, Hanefeld M, Karasik A, Laakso $M$ et al. Acarbose treatment and risk of cardiovascular disease and hypertension in patients with impaired glucose tolerance.the STOP NIDDM trial. JAMA. 2003;290(4):486-90.

84. Shimabukuro M, Higa M, Yamakawa K, Masuzaki H, Sata M. Migital, alpha glucosidase inhibitor reduces visceral fat accumulation and cardiovascular risk factor in subjects with metabolic syndrome.a randomized comparable study.Int $\mathbf{J}$ Cardiol. 2013;167(5):108-13.

85. Hariya $N$, Mochizuki $K$, Inoue $S$, Saito $M$, Fuchigami M, Goda $\mathrm{T}$, et al. Switching alpha glucosidase inhibitors to migital reduced glucose fluctuations and circulatory cardiovascular disease risk factors in type 2 diabetic Japanese patients. D Drugs RD. 2014;14(3):177-84.

86. DiNicolantonio JJ, Bhutani J, O'Keefe JH. Acarbose, safe and effective for lowering post prandial hyperglycemia and improving cardiovascular outcome. Open Heart. 2015;2(1):321.

Cite this article as: Singh PS, Yadav SK, Sharma H, Kumar M. Cardiovascular safety of oral antidiabetic therapy in type 2 diabetes mellitus- review article. Int J Res Med Sci 2017;5:1742-50.

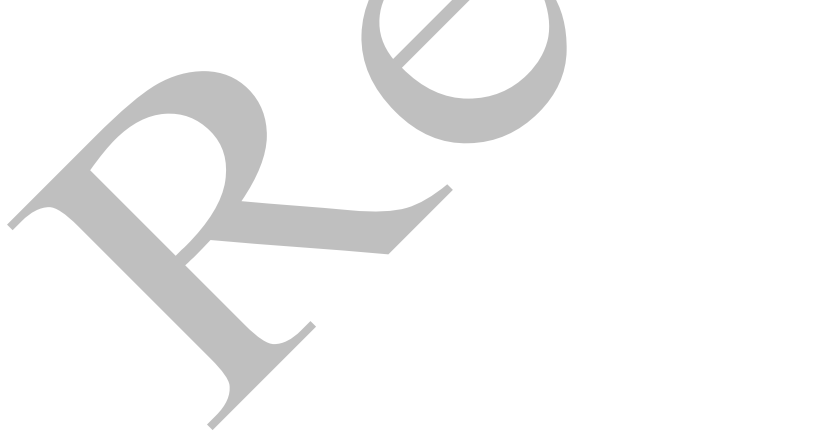

